\title{
Monitoring of the Palladium Concentration in River Water and Sediment at an Acidic Hot Spring Spa Area in Gunma Prefecture
}

\author{
Meichao Zhao, ${ }^{* 1}$ Nobuhiko WADA, ${ }^{* 1, * 2}$ Haruka ShINoZAKI, ${ }^{* 1}$ Noriaki SEKo, ${ }^{* 3}$ Masanobu MorI, $* 4 \dagger$ \\ and Hideyuki ITABASHI*1 \\ *1 Graduate School of Science and Technology, Gunma University, 1-5-1 Tenjin-cho, Kiryu, Gunma 376-8515, \\ Japan \\ *2 Shanghai Shenglong Environment Remediation Technologies, Co., Ltd., Room 801, Building No. 1, 100 Qinzhou \\ Road, Xuhui District, Shanghai 200235, China \\ *3 National Institutes for Quantum and Radiological Science and Technology (QST), Quantum Beam Science \\ Research Directorate, Takasaki Advanced Radiation Research Institute, 1233 Watanuki-machi, Takasaki, \\ Gunma 370-1292, Japan \\ *4 Faculty of Science and Technology, Kochi University, 2-5-1 Akebono-cho, Kochi 780-8520 Japan
}

\begin{abstract}
In an effort to elucidate the deposition pathway of Pd in river sediments, we analyzed the amount of Pd in the river water and sediments of the Yukawa and Yazawa rivers, as well as in the sediments of the Shinaki dam-lake of the Kusatsu hotspring area, which is located northwest in Gunma Prefecture of Japan. The crystal structures and elemental compositions of the river sediment samples differed significantly before and after neutralization. This was attributed to the lime input, which also affected the Pd abundance ratio obtained by the sequential extraction procedure. Additionally, the low leachability of Pd in the sediment suggested possible difficulties in its recovery. Considering the analysis of the Pd variation in the environments, it was concluded that the Pd content in the sediment of the Shinaki dam-lake was mainly supplied by the Yukawa river water inflowing the surrounding tributary rivers and hot-spring waters before neutralization, rather than the lime input.
\end{abstract}

Keywords Palladium, river, dam, sediment, sequential extraction, leachability

(Received May 4, 2018; Accepted August 3, 2018; Advance Publication Released Online by J-STAGE August 17, 2018)

\section{Introduction}

The Kusatsu region, situated northwest in Gunma Prefecture, Japan, is a famous hot-spa area located approximately $1100-1200 \mathrm{~m}$ above sea level at the east foot of Mt. Shirane. ${ }^{1}$ The hot-spring water that originates from the Kusatsu-Shirane volcano has a strongly acidic $\mathrm{pH}$ owing to the presence of significant quantities of sulfuric and hydrochloric acid, as well as large amounts of arsenic and metal ions from the hot springs and volcanic eruptions that flow into the rivers surrounding the hot springs. ${ }^{2}$ To address this issue, acidic river water in the Yukawa, Yazawa, and Osawa tributary rivers has been neutralized through the addition of a lime suspension since 1964..$^{-5}$ This process is carried out at a neutralization factory, and the corresponding quantities of lime introduced into these rivers are 53, 4.1, and 7.4 tons per day. ${ }^{6}$ Since the addition of lime results in a river-water $\mathrm{pH}$ shift to neutral and basic values, any heavy metals present in the water are precipitated as their corresponding hydroxides and/or bound to hydrous ferric oxides (HFOs) to give a suspension. This causes sediments containing precipitates with high heavy metal concentrations to flow into the Shinaki

$\dagger$ To whom correspondence should be addressed.

E-mail: mori@kochi-u.ac.jp dam, thereby necessitating an annual removal by dredging with a high-pressure suction pump.

As a result of this dredging and subsequent dumping, the sediments present in the soil dumping area contain large quantities of arsenic bound to suspended HFOs, and a significant amount of heavy metals. Studies on the leachability of heavy metals from the sediment into ground water or the surrounding areas of the Shinaki dam, using sequential extraction, are therefore of particular interest. ${ }^{7}$ In this context, Kikawada et al. ${ }^{8}$ determined the arsenic concentration in hot-spring water, river water samples collected before and after neutralization, and in precipitates collected from the Shinaki dam. They reported that the largest sources of arsenic were the Bandaiko hot spring and the Yukawa river, with 25 tons of arsenic being deposited in the Shinaki dam annually. In addition, several researchers have focused on the valuable metals present in the hot springs, rivers, and sediments following neutralization. More specifically, Ogawa et al. ${ }^{9}$ compared the fractionation and deposition of indium (In) during transport from the Kusatsu acidic hot springs into the Shinaki dam, and found that it was removed and adsorbed onto a lime suspension before being transferred to the Shinaki dam. Furthermore, Kikawada et al. ${ }^{10}$ elucidated the lanthanide patterns of Kusatsu-Yubatake and Tamagawa-Obuki hot-spring water samples, in which it was apparent that the lighter lanthanides were more easily leached into water than the 
heavier ones.

Previously, we also investigated the leachability of harmful elements, such cadmium $(\mathrm{Cd})$ and lead $(\mathrm{Pb})$, from the sediments of the Watarase river area, using a sequential extraction procedure to ultimately determine any potential influences on the ecosystem and human health. ${ }^{11,12}$ In addition, we have recently focused our investigations on the behavior of platinum group metals (PGMs) in industrial waste and sediments in the rivers and lakes of the Gunma Prefecture. PGMs are commonly employed in catalytic convertors and in the electronic components of mobile phones, ${ }^{13,14}$ and originate from deposited ores and pelagic marine sediments. ${ }^{15,16}$

Through our research, we found relatively high concentrations of palladium (Pd) $(\sim 40 \mu \mathrm{g} / \mathrm{kg})$ in the sediments of the Shinaki dam downstream of the Kusatsu hot spa area (unpublished). Therefore, the existence of a $\mathrm{Pd}$ chemical form that can be easily isolated from the sediment or water may potentially lead to a resource creation.

As such, in this work, we investigated the distribution of Pd by analyzing its concentration in river-water samples obtained across the streams of Yukawa and Yazawa rivers, using inductively coupled plasma mass spectroscopy. Sediment samples collected at the same sampling points of the two rivers and Shinaki dam lake samples were characterized by X-ray diffraction and X-ray fluorescence analyses in order to detect and compare the chemical compositions and crystal structures of the respective components before and after the neutralization process. Additionally, the characterized sediment samples were fractionated by a sequential extraction ${ }^{17}$ to estimate the leachability of Pd from the sediment. This is an effective technique for evaluating the leachability of harmful and valuable metals in soil, sediments, and sludge samples in a stepwise fashion. ${ }^{18-20}$ Furthermore, the variations in the Pd concentration of the river water and hot-spring water samples, and the fractionations of the sediment samples were compared with those of other main elements $(\mathrm{Cu}, \mathrm{Zn}, \mathrm{As}$ and $\mathrm{Cd})$ in order to assist discussions concerning the Pd behavior. Finally, we predicted the $\mathrm{Pd}$ deposition pathway in the Shinaki dam sediment by examining the Pd distributions and different chemical forms present in the river and dam sediments.

\section{Experimental}

\section{Reagents}

All reagents used in this study were purchased from Wako Pure Chemical Industries, Co., Ltd. (Osaka, Japan) and were of analytical grade. The standard solutions were prepared using ultrapure water, which was purified using a water distillation system (ASK-2DS, Iwaki Co., Ltd., Tokyo, Japan). The multielement calibration standards (XSTC-7 and XSTC-13) of the target elements were purchased from SPEX CertiPrep (Metuchen, NJ, USA).

\section{Apparatuses}

Prior to the digestion and speciation analyses, crystal-structure analysis of the collected sediment samples was carried out using X-ray diffraction (XRD, RIGAKU RINT-2200V, Rigaku Corp., Tokyo, Japan). In addition, the major elements in the sediment samples were measured by energy-dispersive fluorescent X-ray analysis (XRF, EA1200VX, Hitachi High-Tech Science Corp., Tokyo, Japan).

Furthermore, the separation of solid materials in water samples, such as sand or slurry in the collected river water and the residues in the extractants in the sequential extraction procedure, were performed by centrifugation (Kokusan H-200, Kokusan Co., Ltd., Tokyo, Japan) at a fixed angle running at $3000 \mathrm{rpm}$. The extraction solution and sediment samples were mixed using a magnetic stirrer (RS-1DW, As-One Corp., Osaka, Japan) equipped with a rotor. During stirring, a constant temperature $\left(25^{\circ} \mathrm{C}\right)$ was maintained with a thermos regulator (CTR-330, Iwaki, Tokyo, Japan). A pH meter with a glasscombined electrode (F-22, Horiba, Ltd., Kyoto, Japan) was used when preparing the solutions. The concentration of the target element in the water samples and extractants of the sequential extraction were determined using inductively coupled plasma mass spectrometry (ICP-MS, Agilent 7700x, Agilent Technology, Santa Clara, CA, USA).

\section{ICP-MS analysis}

Determining the target elements present in the various samples was carried out by ICP-MS (Agilent 7700x-ICP-MS) analysis suing a collision cell to eliminate any interferences (especially ${ }^{40} \mathrm{Ar}{ }^{35} \mathrm{Cl}$ in an analysis of ${ }^{75} \mathrm{As}$ ) with the target elements. ${ }^{21,22}$ Helium (He), a non-reactive gas, was used in the collision cell. Therefore, the element concentrations indicated herein were values obtained via the collision mode with $\mathrm{He}$ (He-mode).

The operating conditions employed are summarized in Table S1 (Supporting Information). Data acquisition and post analysis were carried out using the G201A Mass Hunter Workstation Software, A.01.02 (Agilent Technology, USA). In order to maintain a linear concentration range, the samples were diluted with pure water in the range of $1-1000$-fold, as necessary. Then, $0.5 \%$ nitric acid was added and the solutions were transferred to 14-mL polypropylene tubes (As-One Corporation, Osaka, Japan). Additionally, a background blank sample without extractant was prepared from water and $0.5 \%$ nitric acid. Calibration curves of all the measured elements were prepared from multi-element standard solutions with the concentrations ranging from 0 (blank) to $1 \mu \mathrm{g} \mathrm{L}^{-1}$ for palladium and from 0 (blank) to $10 \mu \mathrm{g} \mathrm{L}^{-1}$ for other elements. The obtained calibration curves exhibited good linearity with correlation coefficients $\left(r^{2}\right)>0.999$. In addition, we employed an internal standard method to determine the metal concentration and to improve the quantitative accuracy of the ICP-MS analysis. In this approach, a mixture of germanium and indium (0.5 mg L $\mathrm{m}^{-1}$ each) was used as an internal standard to determine the ${ }^{63} \mathrm{Cu},{ }^{66} \mathrm{Zn},{ }^{75} \mathrm{As},{ }^{105} \mathrm{Pd}$, and ${ }^{111} \mathrm{Cd}$ concentrations. The detection limits estimated from absolute calibration curves of As, Pd and Cd $(1.0-5.0 \mu \mathrm{g} / \mathrm{L})$ were $0.4,0.002$ and $0.01 \mu \mathrm{g} / \mathrm{L}$, respectively.

\section{Collection of hot spring and river water samples}

Sampling of the hot-spring water, river water, and sediments was undertaken at the Kusatsu hot spring area on 18 October 2016. As shown in Fig. 1, the hot spring and river water samples were collected from a spout of hot spring in Sainokawara park, Yubatake, and Bandaiko springs, as well as from different riverbed locations before and after the neutralization points of the Yukawa and Yazawa rivers. A hot spring water in the Sainokawara park (SP) as a comparison with the river water samples was collected from a spout of a hot spring near a stream that flows along Yukawa river in the park, which is in Kusatsu-cho of Gunma Prefecture ( $36^{\circ} 37^{\prime} 27^{\prime \prime}$ N, $138^{\circ} 35^{\prime} 24^{\prime \prime}$ E). Yubatake spring water (YB) was at the facility located in the center of Kusatsu-cho downtown ( $\left.36^{\circ} 37^{\prime} 22^{\prime \prime} \mathrm{N}, 138^{\circ} 35^{\prime} 48^{\prime \prime} \mathrm{E}\right)$. Bandaiko spring water (BN) was at a hut managed by the Shinaki Dam Water Quality Control Office where poured from the source into the town $\left(36^{\circ} 37^{\prime} 23^{\prime \prime} \mathrm{N}, 138^{\circ} 36^{\prime} 10^{\prime \prime} \mathrm{E}\right)$. The concentrations of $\mathrm{Pd}, \mathrm{Cd}$, and As were determined by ICP-MS; 


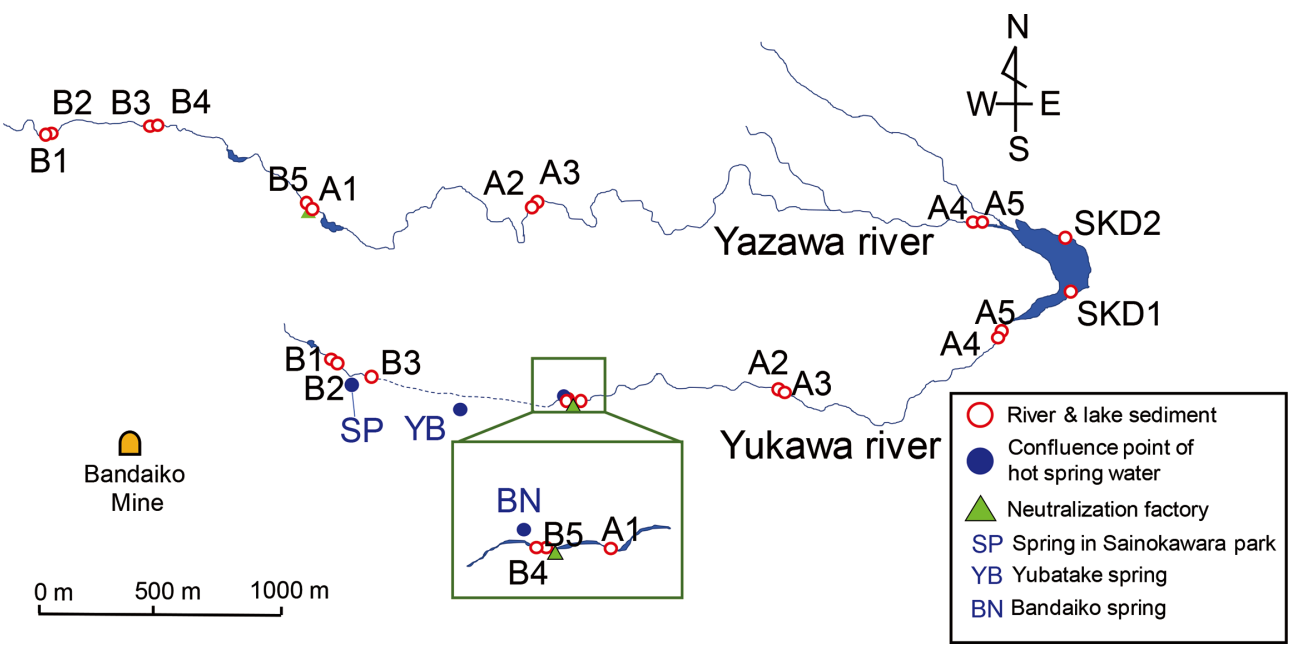

Fig. 1 Map of the sample collection locations. Red circles identify collection points for the river water and sediment samples, blue circles represent the hot springs, and green triangles indicate the neutralization points.

Table 1 Concentrations of Pd, Cd, and As in Sainokawara park, Yubatake and Bandaiko springs

\begin{tabular}{lccc}
\hline \multicolumn{1}{c}{ Sample } & $\mathrm{Pd} / \mu \mathrm{g} \mathrm{L}^{-1}$ & $\mathrm{Cd} / \mu \mathrm{g} \mathrm{L}^{-1}$ & $\mathrm{As} / \mathrm{mg} \mathrm{L}^{-1}$ \\
\hline Sainokawara park & $0.080 \pm 0.049$ & $10.4 \pm 0.1$ & $4.07 \pm 0.10$ \\
Yubatake & $0.053 \pm 0.023$ & $0.554 \pm 0.247$ & $0.340 \pm 0.026$ \\
Bandaiko & $0.048 \pm 0.015$ & $16.3 \pm 1.3$ & $7.19 \pm 0.46$ \\
\hline
\end{tabular}

Average \pm standard deviation obtained by triplicate measurements.

the obtained values are summarized in Table 1. The standard deviations obtained by ICP-MS were relatively large. This would be because the quantitative values were affected the LOD by the 5 - to 1000 -fold dilution of the river water sample as mentioned in experimental section. The vessels containing the water samples were rinsed, and $0.45 \mu \mathrm{m}$ syringe filters were employed to separate the larger particles prior to acidifying with $0.50 \mathrm{vol} \%$ nitric acid to prevent metal precipitation or adsorption on the container surface. The prepared samples were stored in $100-\mathrm{mL}$ polypropylene bottles.

\section{Collection of river and lake sediment samples}

The sediment samples from the rivers and the Shinaki dam $\left(\mathrm{N} 36^{\circ} 37^{\prime}, \mathrm{E} 138^{\circ} 38^{\prime}\right)$ were collected at the points indicated in Fig. 1 (B1 - B5 at an upstream location before the neutralization factory, and A1 - A5 at a downstream location after the factory). Only water samples (i.e., not sediment samples) were collected at points $\mathrm{B} 4$ and $\mathrm{A} 1$ of the Yukawa river, as at these points the river bottom was artificially constructed from cement and stone, and no sediment was precipitated owing to the fast river flow. The sediment samples from the rivers were collected at a depth of $0-5 \mathrm{~cm}$ using a plastic shovel. In contrast, sediment samples (SKD1 and SKD2) from the bottom of the Shinaki dam-lake were obtained from the slurry precipitates, which had been pumped from the dredger to a land facility using a high-pressure pump.

All sediment samples were collected with a soil sampling kit (Daiki Rika Kogyo Co., Ltd., Saitama, Japan) to remove any stone components. After being packed in plastic sachets, the samples were immediately transported to our laboratory. In order to reduce the biological reproduction in the wet sediment samples, the collected samples were air-dried at $25 \pm 1{ }^{\circ} \mathrm{C}$ after they arrived in the laboratory. The dried samples were pulverized using a mortar and pestle, and then sieved to obtain particles with a diameter $<2 \mathrm{~mm}$. Finally, all samples were dried at $60^{\circ} \mathrm{C}$ for $24 \mathrm{~h}$.

\section{Sequential extraction procedure}

Sequential extraction procedures (SEPs) of the target elements present in the sediment samples were carried out according to Tessier's method ${ }^{17}$ to evaluate the potential leachability from the sediment to the river water. The specific details for obtaining each fraction are as follows.

Fraction 1 (exchangeable form): A portion $(1.0 \mathrm{~g})$ of the sediment sample was placed in a $50-\mathrm{mL}$ centrifuge tube, and $1.0 \mathrm{M}$ aqueous $\mathrm{MgCl}_{2}(\mathrm{pH} 7,8 \mathrm{~mL}$ ) was added. After stirring at $600 \mathrm{rpm}$ for $1 \mathrm{~h}$ using a magnetic stirrer, the resulting solidliquid mixture was subjected to centrifugation at $3000 \mathrm{rpm}$ for $30 \mathrm{~min}$. Then, the supernatant was filtered through a $0.45-\mu \mathrm{m}$ syringe filter and the residues were rinsed using ultrapure water $(8.0 \mathrm{~mL})$ by vortexing at $600 \mathrm{rpm}$ for $10 \mathrm{~min}$. The centrifugation and filtration procedures were performed twice. All procedures were carried out at $25 \pm 5^{\circ} \mathrm{C}$.

Fraction 2 (bound to carbonates): Fraction 2 was generated by mixing the residue obtained during the preparation of Fraction 1 with a $1.0 \mathrm{M}$ aqueous $\mathrm{CH}_{3} \mathrm{COONa}$ solution $(\mathrm{pH} 5,8.0 \mathrm{~mL})$ at $25 \pm 5^{\circ} \mathrm{C}$ for $5 \mathrm{~h}$. The centrifugation, filtration, and rinsing procedures described for Fraction 1 were then performed to obtain Fraction 2.

Fraction 3 (bound to iron and manganese-oxide): Fraction 3 was generated by mixing the residue obtained from the preparation of Fraction 2 with a $0.04 \mathrm{M}$ aqueous solution of $\mathrm{NH}_{2} \mathrm{OH} \cdot \mathrm{HCl}$ in $25 \% \mathrm{v} / \mathrm{v} \mathrm{CH}_{3} \mathrm{COOH}(8.0 \mathrm{~mL})$ at $96 \pm 3^{\circ} \mathrm{C}$ for $6 \mathrm{~h}$. After this time, the resulting mixture was subjected to centrifugation at $3000 \mathrm{rpm}$ for $30 \mathrm{~min}$, and the supernatant was collected. The centrifugation, filtration, and rinsing procedures described for Fraction 1 were then performed to obtain Fraction 3.

Fraction 4 (strong acid elution form): Originally, Fraction 4 , which is defined by Tessier et al. ${ }^{17}$ as the species that is bound to organic matter, was prepared upon treatment of the residue obtained during the preparation of Fraction 3 with a mixture of $8.8 \mathrm{M} \mathrm{H}_{2} \mathrm{O}_{2}(8.0 \mathrm{~mL})$ and $0.02 \mathrm{M} \mathrm{HNO}_{3}(3.0 \mathrm{~mL})$ at $85 \pm 2{ }^{\circ} \mathrm{C}$ for $5 \mathrm{~h}$ to elute the species bound to the organic matter. 
(a)

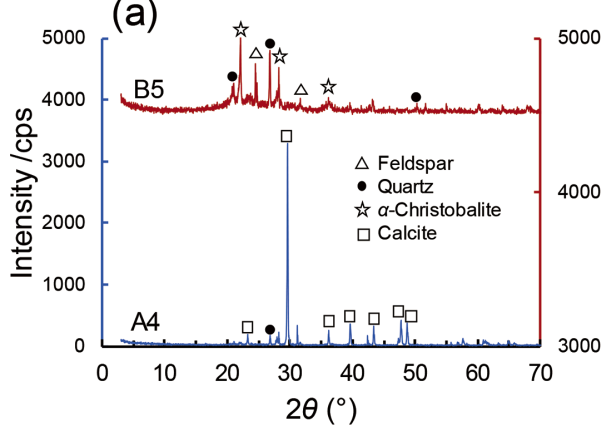

(c)

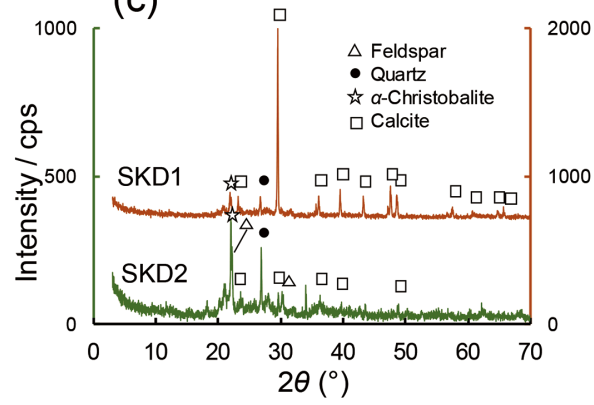

(b)

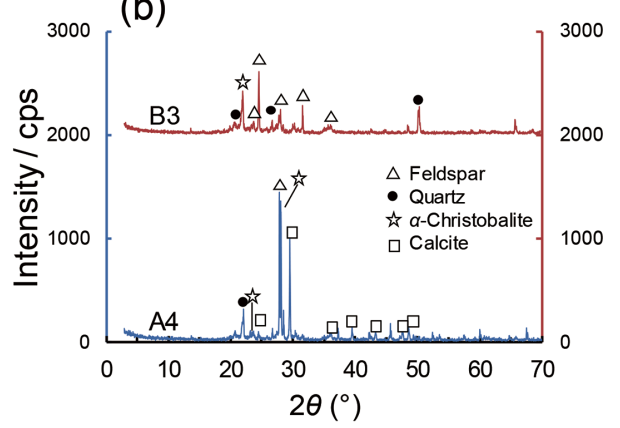

(d)

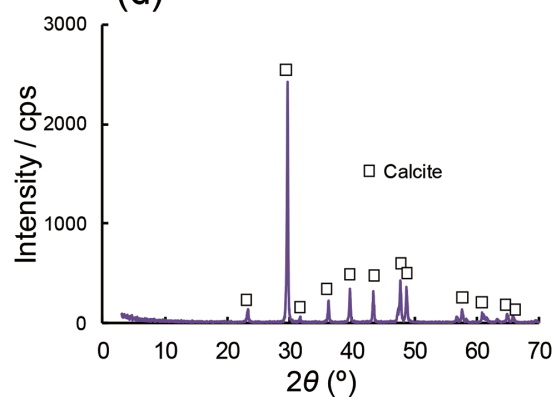

Fig. 2 XRD patterns of the river sediments before and after neutralization from the (a) Yukawa (B5, A4) and (b) Yazawa (B3, A4) rivers, (c) sediment from the Shinaki dam lake (SKD1 and SKD2), and (d) lime used in the neutralization factory.

Importantly, in this process explosive foaming occurred due to the large quantities of calcium carbonate present in the residue. Therefore, we employed an alternative procedure to obtain Fraction 4, in which the residue obtained from the preparation of Fraction 3 was dissolved in a mixture of $36 \%(\mathrm{w} / \mathrm{w}) \mathrm{HCl}$ $(10 \mathrm{~mL})$ and $60 \%(\mathrm{w} / \mathrm{w}) \mathrm{HClO}_{4}(2 \mathrm{~mL})$ and then evaporated the mixture to dryness at $180^{\circ} \mathrm{C}$ in a sand bath. After the further addition of a solution of $36 \%(\mathrm{w} / \mathrm{w}) \mathrm{HCl}(10 \mathrm{~mL})$ and $60 \%$ $(\mathrm{w} / \mathrm{w}) \mathrm{HClO}_{4}(1 \mathrm{~mL})$, the mixture was again evaporated to dryness at $180^{\circ} \mathrm{C}$ for $24 \mathrm{~h}$ in a sand bath. Finally, the dried residue was dissolved in a mixture of $36 \%(\mathrm{w} / \mathrm{w}) \mathrm{HCl}(3 \mathrm{~mL})$ and $60 \%(\mathrm{w} / \mathrm{w}) \mathrm{HClO}_{4}(1 \mathrm{~mL})$, subjected to centrifugation at $3000 \mathrm{rpm}$ for $30 \mathrm{~min}$, and then filtered through a $0.45-\mu \mathrm{m}$ syringe filter.

Analyte concentrations in all obtained fractions were determined by ICP-MS after dilution to $25 \mathrm{~mL}$ using ultrapure water.

According to Tessier's method, ${ }^{17}$ Fraction 5 should be determined the elements by completely dissolving the residue obtained during Fraction 4 in a $\mathrm{HF} / \mathrm{HClO}_{4}$ mixture. However, because the use of HF damaged the quartz torch nebulizer of the ICP-MS, we must skip this procedure.

The resulting weights of the residues per $1 \mathrm{~g}$ sediment sample obtained after this four-step sequential extraction are summarized in Table S2 (Supporting Information).

\section{Results and Discussion}

\section{Characterization of the sediment samples}

Initially, the collected sediment samples were characterized by elemental analysis using XRF and the respective crystal structures were determined with XRD.

The elemental analysis revealed that the amount of calcium in the sediment sample after neutralization was significantly higher than that before the neutralization (Table S3 in Supporting Information). Most specifically, in the Yukawa river, the calcium amount obtained from collection locations A2 to A5 (i.e., A2, A3, A4, A5) decreased slightly from 73.1 to $64.8 \%$, respectively, and the calcium amount in SKD1, which was located near the estuary, was $44.4 \%$. In contrast, in the Yazawa river, the calcium levels from collection locations A1 to A3 were ranging from 70.7 to $42.7 \%$, and the calcium amount in the SKD2 sample was lower than that in the A4 sample.

The XRD patterns of the sediment samples, in turn, revealed an obvious difference between the crystal structures of the samples obtained before and after the neutralization process (Figs. 2a and 2b). Furthermore, the main crystal structure of both sediment samples collected in the Shinaki dam-lake (SKD1 and SKD2) was found be calcite (Fig. 2c). A comparison of the XRD patterns with that of lime used in the neutralization (Fig. 2d) indicates that the surface of the river sediments after neutralization were covered with precipitated lime.

It was assumed that the variations in the calcium levels in the samples collected from the sampling points after the neutralization were related to the difference in the volumes of lime suspension input in the Yukawa (53-ton day ${ }^{-1}$ ) and Yazawa rivers (4.1-ton day $\left.{ }^{-1}\right),{ }^{6}$ and in the flow rates of the Yukawa $\left(33000 \mathrm{~L} \mathrm{~min}^{-1}\right)$ and Yazawa rivers $\left(8800 \mathrm{~L} \mathrm{~min}^{-1}\right){ }^{8}$ Moreover, when comparing the calcite intensities in the XRD patterns of SKD1 and SKD2, one can assume that the difference in the river flow rates affected the distribution of the lime precipitates (Fig. 2c and Table S3).

\section{Variations of $P d$ concentration in the river water}

Next, we investigated the changes in Pd concentration in the water samples collected from the Yukawa and Yazawa rivers. The concentrations of the target elements were determined by ICP-MS in a collision mode using He.

As shown in Fig. 3, the concentration of $\mathrm{Cd}$ in the water of the 
Yukawa river was much higher than that of the Yazawa river. In contrast, the difference between the Pd concentrations of the Yukawa and Yazawa rivers was small. The standard deviations with the analyte concentrations are summarized in Table S4 (Supporting Information).

Notably, the analyte concentrations in water of the Yukawa river exhibited a rapid increase between sampling points B2 and B3, while the Yazawa river showed a slight decrease in analyte concentrations from upstream to downstream. The increase in analyte concentrations between collection locations B2 and B3 observed in the Yukawa river might be due to the inflow of acidic hot-spring water from Sainogawara park $\left(0.08 \mu \mathrm{g} \mathrm{L}^{-1}\right)$ inflowed into a stream river, which flows along Yukawa river. In contrast, no highly acidic hot-spring water is introduced into the waters of the Yazawa river and therefore, no such increase

(a)
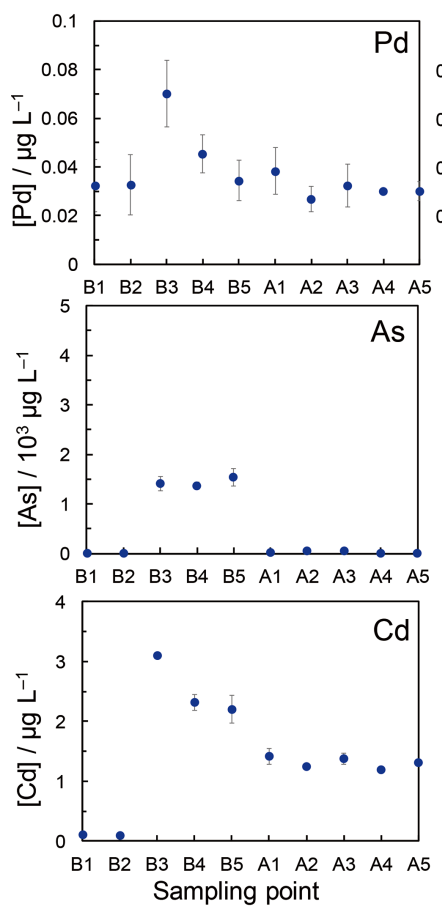

Sampling point (b)
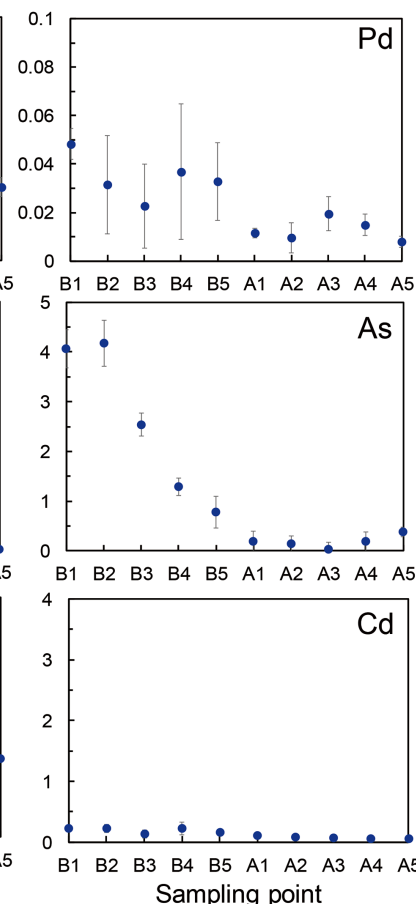

Fig. 3 Concentrations of $\mathrm{Pd}, \mathrm{Cd}$, and $\mathrm{As}$ in river-water samples collected from the (a) Yukawa and (b) Yazawa rivers on 18 October 2016. was observed.

The Pd concentration in the river water following the neutralization decreased by around $0.03-0.04 \mu \mathrm{g} \mathrm{L}^{-1}$, and were almost constant after sample point A5, which was located near the estuary of the Shinaki Lake-dam. Moreover, the concentrations of $\mathrm{Pd}$ and $\mathrm{Cd}$ in both rivers were higher than their limitation of quantifications (LOQs: $c a$. $0.01 \mu \mathrm{g} \mathrm{kg}^{-1}$ ) following the neutralization, whereas the concentration of As was lower than its LOQ. This may be affected by the input lime, which contains $10.5 \mu \mathrm{g} \mathrm{kg}^{-1} \mathrm{Pd}$ and $622 \mu \mathrm{g} \mathrm{kg}^{-1} \mathrm{Cd}$ in a lime sample used in the neutralization factory.

\section{Fractionation of $P d$ in the sediment samples via a sequential} extraction procedure (SEP)

Subsequently, we examined the leachability of Pd deposited in the sediment by fractionation using the SEP, which relies on varying the degrees of solubility. The sediment samples selected for the SEP were from the places where we could collect enough sample amount for repeated experiments.

Prior to the SEP of the sediment samples from the rivers at the Kusatsu hot spring area, we confirmed the precision of the total fractionation of elements in a certified reference material of lake sediment containing trace elements (NMIJ CRM 7303-a). The analyzed elements were $\mathrm{Cu}, \mathrm{Zn}$, and $\mathrm{Cd}$, since $\mathrm{Pd}$ was not included in the certified value displayed in the specification. The total concentrations of these elements obtained by the sequential extraction procedures for Fractions 1-4, and the recoveries of the certified values as summarized in Table S5 (Supporting Information). As results from this experiment, we observed that the total concentrations and recoveries of each element were consequently low compared to the certified values because the sample was not completely dissolved. When comparing these values to the extraction results of $\mathrm{Cu}, \mathrm{Zn}$, and Cd from the same sample (NMIJ-CRM 7303-a) in our previous study (Table S5), ${ }^{23}$ it can be noticed that the experimental $t$-values $\left(\left|t_{\text {exp }}\right|\right)$ of the metals as determined by the paired $t$-test ${ }^{24}$ for every individual metal species at the confidence level of $95 \%$ $(\mathrm{df}=6)$ were in all cases below the critical $t$-value $\left(\left|t_{\text {crit }}\right|=2.77\right)$, i.e., 0.86 for $\mathrm{Cu}, 2.32$ for $\mathrm{Zn}$, and 0.43 for $\mathrm{Cd}$. Therefore, the precisions of the SEP used in this study was maintained.

Figure 4 shows the fractionation of Pd in the sediment samples via the SEP (the concentrations of other elements is shown in Fig. S1 and Table S6, Supporting Information). Moreover, the abundance ratios of the fractionations of all analyte elements are summarized in Table 2.

Notably, the highest Pd concentration prior to the neutralization was recorded for Fraction 4. The abundance ratios of Fractions (a)

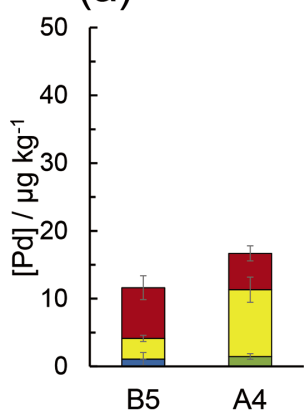

(b)

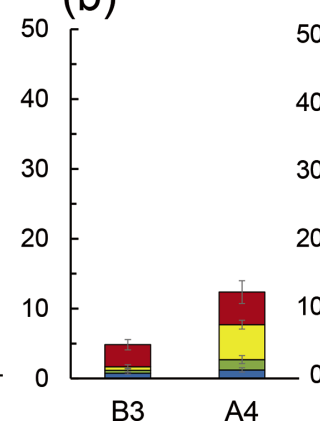

(c)

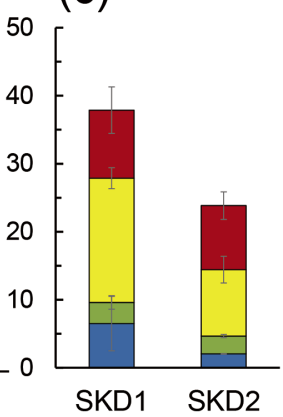

(d)

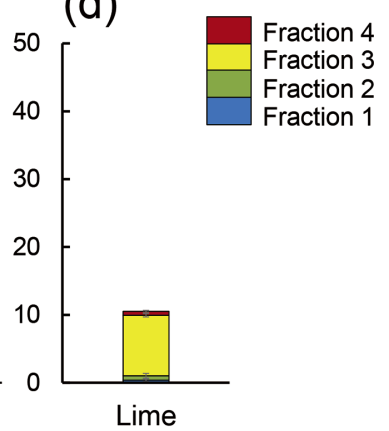

Fig. 4 Concentrations and fractionation of Pd in the various sediment samples from the (a) Yukawa river, (b) Yazawa river, and (c) Shinaki dam lake (SKD1 and SKD2), as well as in (d) lime. The error bars on each bar graph were obtained from the standard deviations in triplicate measurements. 
Table 2 Concentrations of the fractionations and abundance ratios of $\mathrm{Pd}$ in the sediment and lime samples used in the neutralization

\begin{tabular}{|c|c|c|c|c|c|c|c|}
\hline \multirow{2}{*}{$\frac{\text { Concentration } / \mathrm{mg} \mathrm{kg}^{-1}}{\text { Sampling point }}$} & \multicolumn{2}{|c|}{ Yukawa river } & \multicolumn{2}{|c|}{ Yazawa river } & \multicolumn{2}{|c|}{ Shinaki dam } & \multirow{2}{*}{$\frac{\text { Lime }}{\text { Neutralization }}$} \\
\hline & B5 & A4 & B3 & A4 & SKD1 & SKD2 & \\
\hline Fraction 1 & $1.09 \pm 0.95$ & N.D. & $0.754 \pm 0.119$ & $1.22 \pm 0.30$ & $6.50 \pm 3.99$ & $2.05 \pm 0.05$ & 0.365 \\
\hline Fraction 2 & N.D. & $1.46 \pm 0.40$ & $0.420 \pm 0.255$ & $1.48 \pm 0.56$ & $3.11 \pm 1.00$ & $2.62 \pm 0.24$ & 0.660 \\
\hline Fraction 3 & $3.05 \pm 0.46$ & $9.86 \pm 1.85$ & $0.499 \pm 0.288$ & $5.00 \pm 0.64$ & $18.3 \pm 1.54$ & $9.76 \pm 1.96$ & 8.92 \\
\hline Fraction 4 & $7.48 \pm 1.75$ & $5.36 \pm 1.12$ & $3.17 \pm 0.74$ & $4.67 \pm 1.63$ & $10.0 \pm 3.4$ & $9.41 \pm 2.03$ & 0.570 \\
\hline Abundance ratio, $\%$ & \multicolumn{2}{|c|}{ Yukawa river } & \multicolumn{2}{|c|}{ Yazawa river } & \multicolumn{2}{|c|}{ Shinaki dam } & Lime \\
\hline Sampling point & B5 & A4 & B3 & A4 & SKD1 & SKD2 & Neutralization \\
\hline Fraction 1 & 9.4 & - & 15.6 & 9.9 & 17.2 & 8.6 & 3.5 \\
\hline Fraction 2 & - & 8.8 & 8.7 & 12.0 & 8.2 & 11.0 & 6.3 \\
\hline Fraction 3 & 26.2 & 59.1 & 10.3 & 40.4 & 48.3 & 40.9 & 84.8 \\
\hline Fraction 4 & 64.4 & 32.1 & 65.4 & 37.8 & 26.4 & 39.5 & 5.4 \\
\hline
\end{tabular}

Average \pm standard deviation obtained by triplicate measurements, except for lime. N.D.: not detected.

1 and 2, which are easy elution-forms, suggest that the leachability of $\mathrm{Pd}$ from the sediment to the river was lower than $10 \%\left(1.0 \pm 0.9 \mu \mathrm{g} \mathrm{kg}^{-1}\right)$. In fact, if the residue obtained after Fraction 4 was completely dissolved in a $\mathrm{HF} / \mathrm{HClO}_{4}$ solution, the ratio was expected to be further decreased. The abundance ratios of $\mathrm{Pd}$ in the sediment obtained after the neutralization of the Yukawa and Yazawa rivers decreased in the following order: Fraction $3>$ Fraction $4>$ Fraction 2 . However, the fact that the main fractionation of lime was contained in Fraction $3(84.8 \%)$ indicated that the increase in Pd concentration in Fraction 3 after the neutralization was affected by the input of lime suspension (Table 2). The changes in the abundance ratio of the fractions before and after neutralization were considered through XRD pattern of the residues obtained following each fractionation. As shown in Fig. 5b, the calcite in the residue obtained after Fraction 3 in A4, where was collected from place after imputing lime, was not almost observed, compared to those of the Fractions 1 and 2. No changes in XRD patterns of residues in four fractions at B5 (Fig. 5a), where was collected from the place before imputing line, was obtained. The main contents of sediment sample in B5 were expected to be silicate, such as feldspar, quartz and $\alpha$-cristobalite as well as calcite, considering the data in XRF (Table S3). Namely, adding lime strongly affects the composition of the sediment surface.

Also, Fraction 2 in A4 was enhanced by the neutralization, against Fraction 1 in B5 was reduced. The elemental analysis by XRF (Table S3 in Supporting Information) suggests that the solubility of $\mathrm{Pd}$ sediments may be decreased with binding to carbonate such as $\mathrm{CaCO}_{3}$ or $\mathrm{HCO}_{3}{ }^{-} / \mathrm{CO}_{3}{ }^{2-}$ in Fraction 2 (Fig. 4).

Interestingly, the $\mathrm{Pd}$ fractionation results from the Shinaki dam were comparative to those from the river sediments following the neutralization, thereby indicating that the Pdcontaining sediment moves downstream into the Shinaki dam. Moreover, the total $\mathrm{Pd}, \mathrm{Cd}$, and As concentrations in SKD1, which is located near the Yukawa estuary, was higher than that in SKD2, situated near the Yazawa estuary.

Furthermore, the leachability of Pd from the sediment was found to be lower than those of homologous elements such as $\mathrm{Cd}$ and $\mathrm{Zn}$, because the easily eluted form of Pd exhibited not only low abundance ratios in Fractions 1 and 2 but also a low absolute amount.

Pathway of Pd precipitation in the sediment of Shinaki dam-lake In order to discuss the pathway of Pd precipitation in the sediment of Shinaki dam, the Pd amount in each sampling point

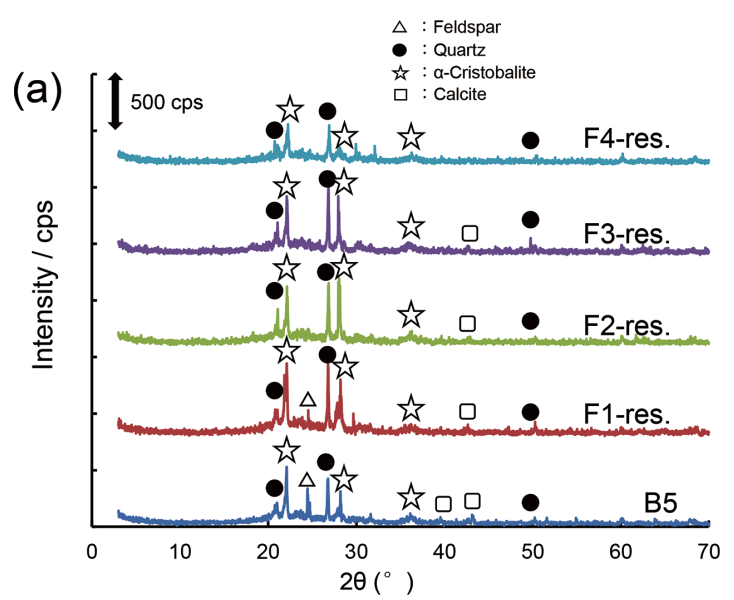

(b)

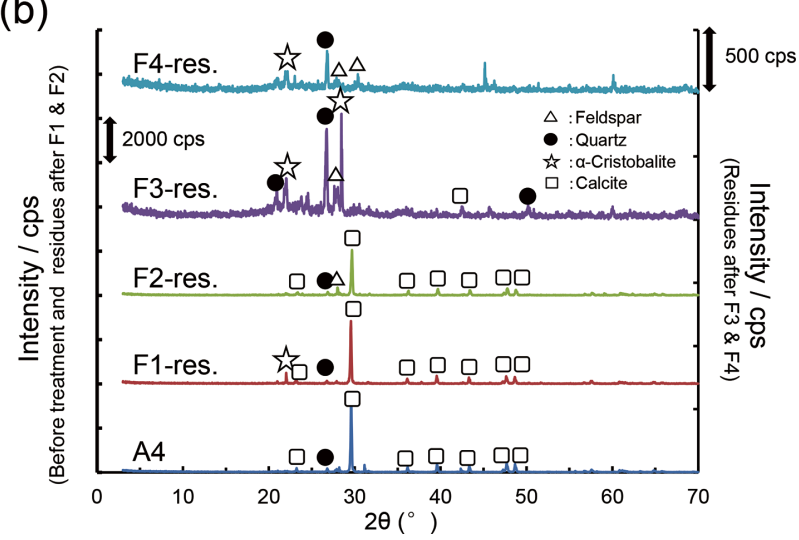

Fig. 5 XRD patterns of residues after each fractionation of Yukawa river sediment by sequential extraction procedure (SEP). Sampling point: (a) B5 (before neutralization factory) and (b) A4 (after neutralization factory). The bottom pattern is before SEP. F1-res.: residue of Fraction 1, F2-res.: residue of Fraction 2, F3-res.: residue of Fraction 3 and F4-res.: residue of Fraction 4.

was calculated.

In the river sediments after the neutralization, the $\mathrm{Pd}$ concentrations and the fractionation by the SEP seemed to be affected by lime inputting. However, the estimations of the Pd 
Table 3 Daily transitions of Pd in the Kusatsu hot-springs area

\begin{tabular}{|c|c|c|c|}
\hline Inflow sources & Concentrations of Pd in water sample & Daily flow rate ${ }^{b}$ & Pd amount \\
\hline Yazawa river & $0.034 \pm 0.009 \mu \mathrm{g} / \mathrm{L}^{\mathrm{a}}$ & $(16.0 \pm 9.9) \times 10^{3} \mathrm{~m}^{3} / \mathrm{day}^{\mathrm{b}}$ & $0.551 \mathrm{~g} /$ day \\
\hline Yukawa river & $0.043 \pm 0.016 \mu \mathrm{g} / \mathrm{L}^{\mathrm{a}}$ & $(68.4 \pm 13.5) \times 10^{3} \mathrm{~m}^{3} / \mathrm{day}^{\mathrm{b}}$ & $2.93 \mathrm{~g} / \mathrm{day}$ \\
\hline Bandaiko spring & $0.048 \pm 0.015 \mu \mathrm{g} / \mathrm{L}$ & $(12.8 \pm 0.7) \times 10^{3} \mathrm{~m}^{3} / \mathrm{day}^{\mathrm{c}}$ & $0.607 \mathrm{~g} /$ day \\
\hline Lime inputted & Total concentration of Pd in Fractions $1-4$ by SEP & Daily lime input into river at neutralization ${ }^{\mathrm{d}}$ & Pd amount \\
\hline \multirow[t]{3}{*}{ Lime (solid) } & $10.2 \mu \mathrm{g} / \mathrm{kg}$ & Osawa riv. & $0.075 \mathrm{~g} /$ day \\
\hline & & Yazawa riv. & $0.042 \mathrm{~g} /$ day \\
\hline & & Yukawa riv. & $0.541 \mathrm{~g} /$ day \\
\hline Lake sediments & Total concentration of Fractions $1-4$ by SEP & Annual dredging ${ }^{\mathrm{d}}$ & Pd amount \\
\hline SKD1 & $37.9 \pm 9.7 \mu \mathrm{g} / \mathrm{kg}$ & $15.5 \mathrm{kt} /$ year (42.5 t/day) & $588 \mathrm{~g} /$ year $(1.61 \mathrm{~g} /$ day $)$ \\
\hline SKD2 & $23.8 \pm 2.9 \mu \mathrm{g} / \mathrm{kg}$ & & $369 \mathrm{~g} /$ year $(1.01 \mathrm{~g} /$ day $)$ \\
\hline
\end{tabular}

a. Average Pd concentration in the Yukawa and Yazawa rivers (B1 - B5) before the neutralization. b. Daily flow rates $(Q)$ of the rivers were estimated by Square dam's formula (JIS K0094) using the water level data investigated by Shinaki Dam Water Quality Control Office (Ministry of Land, Infrastructure and Transport Kanto Regional Development Bureau) as following; $Q=1.838(w-0.2 h) h^{3 / 2} \times 60$, where $Q$ is flow quantity, $w$ is notch width of river and $h$ is overflow level. c. Daily flow rate of the Bandaiko spring was data provided by Kusatsucho office. d. The values were the monitoring data obtained by the Shinaki Dam Water Quality Control Office (Ministry of Land, Infrastructure and Transport Kanto Regional Development Bureau).

amounts from the daily inputs of lime in the Yukawa and Yazawa rivers were lower than those in their river waters before the lime inputting as summarizing in Table 3. Because the variation of the Pd concentration in the river water was smaller than those of As and $\mathrm{Cd}$ (Fig. 3), the Pd dissolved in the river water before the neutralization may reach the Shinaki dam-lake. Accordingly, the large amount of Pd precipitated in the lake sediment would mostly originate from Pd dissolved in the Yukawa river, while still being somewhat affected by the lime input. One of the main supply sources of Pd in the river water was considered to be the Bandaiko spring. However, as the Pd amount per daily flow rate in Table 3, the sources of Pd in the rivers of Kusatsu hot spring area would also be included from the tributary rivers and hot spring water of several volcanos surrounding Bandaiko.

\section{Conclusions}

Herein, we investigated the distribution and fractionation of Pd in the river water and sediments of the Yukawa and Yazawa rivers, and the Shinaki dam. As a result, we found that the concentration of Pd in the river water was slightly affected by the addition of a lime suspension, which contains trace amounts of Pd. Moreover, the leachability of Pd from the sediment following the neutralization was found to be extremely low compared to that of other metals, despite the ease of elution obtained by the sequential extraction procedure. Consequently, it was expected that the Pd content in the sediment of the Shinaki dam-lake was supplied by the Yukawa river inflowing spring from Bandaiko mine, tributary rivers and hot spring water, rather than the sediment with precipitated Pd from the lime input during the neutralization.

Considering the continuous rising of the market price of Pd (33,030 US\$/kg at 29 Nov., 2017), ${ }^{25}$ the recovery of Pd from the sediment may be required. However, taking into account the findings of this study, it is likely that this will not be an easy process because of the large amount of acids and reductants needed to extract Pd.

\section{Acknowledgements}

We are grateful to the Shinaki dam water quality management office of the Kanto Regional Bureau of Ministry of Land, Infrastructure, Transport, and Tourism for providing several samples for analysis, in addition to data regarding the water levels and $\mathrm{pH}$ values. Additionally, we would like to thank Ms. H. Amada of the National Institute for Quantum and Radiological Science and Technology for assisting in determining the analyte concentrations by ICP-MS.

\section{Supporting Information}

Table S1 summarizes the ICP-MS operating conditions used in this study. Table S2 summarizes the weights of the residues obtained after the proposed SEP. Table S3 summarizes the abundance ratios of the elements in the sediment samples determined by XRF. Table S4 summarizes the average concentrations and standard deviations of $\mathrm{Pd}, \mathrm{Cd}$, and $\mathrm{As}$ in river water samples. Table S5 summarizes the concentrations and recoveries of trace elements in CRM extracted via a previously reported SPE. Table S6 summarizes each concentration in its fractionation. Figure $\mathrm{S} 1$ shows the concentrations and fractionations of $\mathrm{Cu}, \mathrm{Zn}$, As, and $\mathrm{Cd}$ of the various sediment samples. This material is available free of charge on the Web at http://www.jsac.or.jp/analsci/.

\section{References}

1. Nurhasan, Y. Ogawa, N. Ujihara, S. B. Tank, Y. Honkura, S. Onizawa, T. Mori, and M. Makino, Earth, Planets Space, 2006, 58, 1053.

2. Y. Kikawada, T. Ono, K. Ogawa, M. Fukai, and T. Oi, Procedia Earth Planet. Sci., 2017, 17, 253.

3. H. Muto, Proc. Jpn. Soc. Civil Eng., 1978, 275, 41 (in Japanese).

4. R. E. Villanueva-Estrada, R. M. Prol-Ledesma, A. A. Rodríguez-Díaz, C. Canet, and M. A. Armienta, Chem. 
Geol., 2013, 348, 27.

5. D. Mitsuya, T. Hayashi, Y. Wang, M. Tanaka, M. Okai, M. Ishida, and N. Urano, J. Biosci. Bioeng., 2017, 124, 43.

6. Shinaki Dam Water Quality Control Office, Ministry of Land, Infrastructure and Transport Kanto Regional Development Bureau, http://www.ktr.mlit.go.jp/ktr_content/ content/000076767.pdf.

7. R. E. Price and T. Pichler, Chem. Geol., 2005, 224, 122.

8. Y. Kikawada, S. Kawai, K. Shimada, and T. Oi, J. Disaster Res., 2008, 3, 261.

9. Y. Ogawa, D. Ishiyama, N. Shikazono, K. Iwane, M. Kajiwara, and N. Tsuchiya, Econ. Geol., 2013, 108, 1641.

10. Y. Kikawada, T. Oi, T. Ossaka, H. Kakihana, and T. Honda, Geochem. J., 1995, 29, 67.

11. K. Nakano, M. Sato, A. Tsuda, H. Sekiya, M. Mori, and H. Itabashi, Bunseki Kagaku, 2010, 59, 829.

12. Y. Saito, M. Mori, K. Tsunoda, and H. Itabashi, Kankyo Kagaku, 2012, 25, 422.

13. K. Ravindra, L. Bencs, and R. Van Grieken, Sci. Total Environ., 2004, 318, 1.

14. I. A. Okorie, J. Enwistle, and J. R. Dean, Curr. Sci., 2015, 109, 938.

15. A. J. Naldrett and J. M. Duke, Science, 1980, 208, 1417

16. S. Terashima, N. Mita, S. Nakao, and S. Ishihara, Bull.
Geol. Surv. Jpn., 2002, 53, 725.

17. A. Tessier, P. G. C. Campbell, and M. Bisson, Anal. Chem., 1979, 51, 844.

18. B. P. Cid, A. F. Alborés, E. F. Gómez, and E. F. López, Anal. Chim. Acta, 2001, 431, 209.

19. M. K. Jamali, T. G. Kazi, M. B. Arain, H. I. Afridi, N. Jalbani, G. A. Kandhro, A. Q. Shah, and J. A. Baig, J. Hazard. Mater, 2009, 163, 1157.

20. A. Sungur, M. Soylak, E. Yilmaz, S. Yilmaz, and Hasan Ozcan, Soil Sediment Contam., 2015, 24, 1.

21. E. McCurdy and G. Woods, J. Anal. At. Spectrom., 2004 19, 607.

22. J. W. Olesik and D. R. Jones, J. Anal. At. Spectrom., 2006, 21,141

23. M. Mori, K. Nakano, M. Sasaki, H. Shinozaki, S. Suzuki, C. Okawara, M. Miró, and H. Itabashi, Talanta, 2016, 148, 617.

24. NIST/SEMATECH e-Handbook of Statistical Methods, Chap. 1.3.6.7.2., Critical Values of the Student's-t Distribution, https://www.itl.nist.gov/div898/handbook/eda/ section3/eda3672.htm

25. Investment Mine HP, 5 Year Palladium Prices and Price Charts, http://www.infomine.com/investment/metal-prices/ palladium/5-year/. 